Check for updates

Cite this: RSC Adv., 2019, 9, 11312

\title{
Zinc oxide nanocrystals as a nanoantibiotic and osteoinductive agent $\uparrow$
}

\author{
Nadia Garino, (D) $\dot{t}^{\mathrm{ab}}$ Pasquale Sanvitale, $\dot{t}^{\mathrm{a}}$ Bianca Dumontel, ${ }^{\mathrm{a}}$ Marco Laurenti, ${ }^{\mathrm{a}}$ \\ Montserrat Colilla, (D) cd Isabel Izquierdo-Barba, (D) ${ }^{\text {cd }}$ Valentina Cauda (D) *a \\ and Maria Vallet-Regi (D) *cd
}

In this paper we aim to analyse the behaviour of $\mathrm{ZnO}$ nanocrystals ( $\mathrm{nnO} N C s$ ), prepared with a new synthetic approach and not embedded in any composite matrix, for bone implant applications in vitro. In particular, we have developed a novel, fast and reproducible microwave-assisted synthesis, to obtain highly-crystalline, round-shaped $\mathrm{ZnO} N C s$ of $20 \mathrm{~nm}$ in diameter as an extremely-stable colloidal solution in ethanol. The nanocrystals were also partially chemically functionalized by anchoring amino-propyl groups to the $\mathrm{ZnO}$ surface $\left(\mathrm{ZnO}-\mathrm{NH}_{2} \mathrm{NCs}\right.$ ). Thus, the role of both $\mathrm{ZnO} \mathrm{NC}$ concentration and surface chemistry were tested in terms of biocompatibility towards pre-osteoblast cells, promotion of cell proliferation and differentiation, and also in terms of antimicrobial activity against Gram positive and negative bacteria, such as Escherichia coli and Staphylococcus aureus, respectively. The results suggest that $\mathrm{ZnO}-\mathrm{NH}_{2} \mathrm{NCs}$ is the most promising candidate to solve infectious disease in bone implants and at the same time promote bone tissue proliferation, even at high concentrations. Although further investigations are needed to clarify the mechanism underlying the inhibition of biofilm formation and to investigate the role of the $\mathrm{ZnO}-\mathrm{NH}_{2} \mathrm{NCs}$ in in vivo assays, we demonstrated that fine and reproducible control over the chemical and structural parameters in $\mathrm{ZnO}$ nanomaterials can open up new horizons in the use of functionalized ZnO NCs as a highly biocompatible and osteoinductive nanoantibiotic agent for bone tissue engineering.

Received 13th December 2018

Accepted 27th March 2019

DOI: $10.1039 / c 8 r a 10236 h$

rsc.li/rsc-advances

\section{Introduction}

Nowadays, infections due to both Gram positive and negative pathogens are developing an evolved resistance to conventional antibiotics, impairing the effects of these drugs and posing serious problems to public health in the long term. Bone infections related to the implantation of orthopaedic implants are also facing this important antibiotic resistance issue. In particular, during the insertion of orthopaedic implants, bacteria from patient's skin or mucosa can enter and adhere to the surface of the implant and start to produce an antibiotic-resistant biofilm. This phenomenon results in osteomyelitis, localised bone destruction,

${ }^{a}$ Department of Applied Science and Technology, Politecnico di Torino, Corso Duca degli Abruzzi 24, 10129 Turin, Italy. E-mail: valentina.cauda@polito.it

${ }^{b}$ Istituto Italiano di Tecnologia, Center for Sustainable Future Technologies, Via Livorno 60, 10144 Torino, Italy

'Departamento de Quimica en Ciencias Farmacéuticas, Universidad Complutense de Madrid, Plaza Ramón y Cajal s/n, 28040 Madrid, Spain.E-mail: vallet@ucm.es

${ }^{d}$ Networking Research Center on Bioengineering, Biomaterials and Nanomedicine (CIBER-BBN), Madrid, Spain

$\dagger$ Electronic supplementary information (ESI) available: ZnO NC size distribution curves in ethanol and water, Fourier-transform infrared (FT-IR) spectra, additional fluorescence microscope images, cell differentiation assays in term of total protein content, and cell morphology evaluation by optical microscopy. See DOI: $10.1039 / \mathrm{c} 8 \mathrm{ra} 10236 \mathrm{~h}$

\$ These authors contributed equally. prolonged hospitalisation, intense antibiotic treatment and, in the most serious cases, the replacement of the prosthesis. ${ }^{1}$

It is thus necessary to start exploring either new antibiotic formulations or novel inhibition pathways to solve bacterial resistance. Unfortunately, there is no certainty about the effectiveness of new antimicrobial drugs because bacteria can develop resistance in a timely manner. A new approach to overcome this challenging and infectious disease can be the use of antimicrobial nanomaterials. At first, nanomaterials were proposed as carriers for antibiotics to improve their pharmacokinetics and accumulation, and to reduce side effects. ${ }^{2,3} \mathrm{~A}$ more innovative approach is the use of intrinsicallyantimicrobial nanomaterials, where the antimicrobial activity is not as a result of the pharmaceutical effect of an antibiotic, but instead comes directly from the intrinsic properties of the nanosized material. ${ }^{4}$ To this end, several metal and metal oxide micro- and nano-structures have been proposed due to their ability to produce reactive oxygen species or dissolve in cations, both toxic for the majority of microbial cells. ${ }^{5}$

Among them, zinc oxide ( $\mathrm{ZnO})$ is one of the most promising inorganic antimicrobial materials. At the bulk or micro-sized level, it shows reduced toxicity to eukaryotic cells (it is actually considered a GRAS - generally recognized as safe-substance approved by the US Food and Drug Administration (FDA $)^{6}$ ) and can overcome bacterial resistance to a certain extent. ${ }^{5,7}$ 
The use of nanosized $\mathrm{ZnO}$ in biomedical applications, ${ }^{\mathbf{8 , 9}}$ in particular in bone tissue engineering, can be envisioned owing to its excellent antimicrobial properties, its biocompatibility and partial biodegradability, ${ }^{10}$ facile synthetic approaches can be used to produce materials with different sizes and shapes, ${ }^{\mathbf{1 1}}$ and easily functionalizable surface. ${ }^{12}$ However, some issues are still unsolved concerning its potential toxicity to eukaryotic cells, which can impair either healthy or tumor cells at different dosages. ${ }^{13,14}$ Thus, the use of $\mathrm{ZnO}$ as a nanoantibiotic ${ }^{4}$ requires a careful evaluation of the interactions between the nanomaterials and living cells, tissues and adjacent organs, and thus of dose administration and recalibration in the desired antimicrobial therapy.

The antibacterial activity of $\mathrm{ZnO}$ nanostructures is related to three main probable mechanisms: ${ }^{9}$ (i) reactive oxygen species (ROS) generation, (ii) release of $\mathrm{Zn}^{2+}$ cations and (iii) nanoparticle action. ROS generation is the predominant mechanism and is promoted by the presence of crystalline defects in nanosized $\mathrm{ZnO}$ structures, even in the absence of any photoactivation stimulus. Due to the semiconductor band structure of $\mathrm{ZnO}$, the electrons $\left(\mathrm{e}^{-}\right)$are promoted in the conduction band, whereas unpaired holes $\left(\mathrm{h}^{+}\right)$remain in the valence bands. The migration of both $\mathrm{e}^{-}$and $\mathrm{h}^{+}$at the surface of the nanomaterials promotes their combination with water-adsorbed molecules, generating ROS, such as hydroxyl radicals, singlet oxygen and superoxide radicals. Hydroxyl radicals are the most reactive species and they can quickly interact with every type of biological molecules.

The release of $\mathrm{Zn}^{2+}$ ions from $\mathrm{ZnO}$ nanostructures, owing to their chemical instability in biological media, ${ }^{\mathbf{1 0}}$ is another important mechanism in the antibacterial activity of $\mathrm{ZnO} . \mathrm{Zn}^{2+}$ ions can adsorb to the negatively charged bacteria surface through electrostatic forces. This interaction leads to the loss of the charge balance and deformations of the cell occur with consequent bacteriolysis. At the same time, $\mathrm{Zn}^{2+}$ can penetrate the cell membrane and interact with functional groups as sulphate and phosphate groups, resulting in the structural change of proteins, provoking the destruction of bacteria by unbalanced metabolism.

Finally, the penetration of $\mathrm{ZnO}$ nanoparticles through the bacterial membrane and its consequent disorganisation also leads to bacterial death and thus, this is the third mechanism to take into account. This phenomenon is specifically due to the high specific area and surface energy of $\mathrm{ZnO}$ nanomaterials, which are able to adsorb and accumulate at the membrane and in the cytoplasm.

Despite these most probable mechanisms against bacteria, the influence of the medium components, and the different sizes and surface chemistry of $\mathrm{ZnO}$ nanomaterials also have to be taken into account. Therefore, the real antimicrobial mechanisms are still under investigation and have to be proven depending on the $\mathrm{ZnO}$ morphology, chemical reactivity and surface, and also the bacteria cell type..$^{15}$

It is thus crucial to control the ZnO particles' size, morphology and surface chemistry to efficiently tune on the one hand the antibacterial properties and on the other hand the biocompatibility towards healthy cells in case of biomedical implants or drug delivery devices. ${ }^{\mathbf{1 6}}$
Regarding the specific use of $\mathrm{ZnO}$ nanomaterials for bone tissue engineering, $\mathrm{ZnO}$ was proposed as a suitable filler in composite matrices based on hydroxyapatite, ${ }^{17,18}$ graphene oxide, ${ }^{19}$ polymers, ${ }^{20,21}$ or as a coating for orthopaedic and dental implants, promoting antibacterial response together with osteoblast growth, adhesion and their metabolic activity. ${ }^{22}$ Colon et $a .^{23}$ have analysed the effects of $\mathrm{ZnO}$ micro- and nano-powders, pressed into compacts, on osteoblast functions and $S$. epidermidis adhesion. The results of this study provided the first evidence of significantly greater osteoblast adhesion, alkaline phosphatase (ALP) activity, and calcium mineral deposition on nanophase $\mathrm{ZnO}$ with respect to the microphase counterpart, as well as a reduction in $S$. epidermidis adhesion. Moreover, it was reported that an appropriate concentration of zinc ions can enhance osteoblast cell proliferation and differentiation, ${ }^{24}$ promoting ALP activity and osteocalcin (OCN) secretion, considered as early and major markers of late stage osteoblast differentiation, respectively. ${ }^{25}$

The aim of this study is to analyse the behaviour of $\mathrm{ZnO}$ nanocrystals (ZnO NCs), not embedded in any composite matrix, for bone implants applications in vitro. We have developed a novel microwave-assisted synthesis to obtain ZnO NCs in a fast, highly-reproducible and efficient way. Such NCs, $20 \mathrm{~nm}$ in diameter and with a high degree of crystallinity, can also be chemically functionalized with amine groups, in order to investigate in vitro the effects of their surface chemistry and charge.

Thus, the role of $\mathrm{ZnO} \mathrm{NC}$ concentration and functionalization was tested both in terms of biocompatibility related to preosteoblast cells, promotion of cell proliferation and differentiation, and also in terms of antimicrobial activity against Gram positive and negative bacteria, such as Escherichia coli and Staphylococcus aureus. The results show the promising behaviour of amine-functionalized $\mathrm{ZnO}$ NCs for bone tissue engineering, even at high concentrations, leading to promoted osteogenic behaviour and high antimicrobial activity. It is thus demonstrated that fine control over the chemical and structural parameters in $\mathrm{ZnO}$ nanomaterials can open up new horizons in the use of functionalized $\mathrm{ZnO}$ NCs as a highly biocompatible nanoantibiotic for bone tissue engineering.

\section{Results and discussion}

In this work, we developed a novel wet-chemical synthetic approach to obtain tiny and homogeneous ZnO NCs. The used approach involves a fast, highly-reproducible and efficient microwave-assisted synthesis method, ${ }^{26}$ hydrolysing the zinc acetate dehydrate precursor in a polar solvent (methanol) in the presence of potassium hydroxide. The microwave-assisted solvothermal synthesis shows various advantages with respect to conventional synthetic procedures. In fact, due to the rapid and homogeneous heating it is possible to guarantee very fast kinetic rates and short reaction times, low energy consumption and simultaneous nucleation of nanocrystals that lead to the obtaining of a uniform and reproducible dimensional range. ${ }^{27}$

Thanks to this process, highly-dispersed, round-shaped nanocrystals as an extremely-stable colloidal solution in 
ethanol and water were finally obtained. A portion of them were also chemically modified by anchoring amino-propyl groups to the $\mathrm{ZnO}$ surface, as previously reported. ${ }^{10,28,29}$ The produced nanomaterials were then characterized as described below.

\section{Morphological and structural characterization of the ZnO NCs}

X-ray diffraction (XRD) was performed in order to obtain information about phase identification, along with phase quantification, percentage of crystallinity, crystallite size and unit cell size. Fig. 1a and b show the XRD patterns of the pristine $\mathrm{ZnO}$ NCs and $\mathrm{ZnO}-\mathrm{NH}_{2}$ NCs. A comparison of the patterns with the data bank (JCPDS 36-1451) confirmed the crystalline structure of the particles. In particular, the peaks at $31.9^{\circ}, 34.4^{\circ}$, $36.4^{\circ}, 47.6^{\circ}, 56.7^{\circ}$ can be indexed to the (100), (002), (101), (102) and (110) planes, respectively. These correspond to the Miller indexes of hexagonal wurtzite structured $\mathrm{ZnO}$, according to the literature ${ }^{30,31}$ and are comparable with the standard reference pattern of ZnO. It is also clear that the chemical functionalization did not alter the crystalline structure of $\mathrm{ZnO}$. By using the Debye-Scherrer formula and considering the dominant peaks, it was possible to estimate the dimension of the crystallites, as around $15 \mathrm{~nm}$ for both pristine and functionalized $\mathrm{ZnO}$ NCs.

Transmission electron microscopy (TEM) studies confirmed these results and allowed additional information to be obtained about the particle morphology and size (Fig. 1c and d), in both cases showing a similar polygonal shape, typical of ZnO NCs. The stability behaviour of the ZnO NCs showed highly

(a)

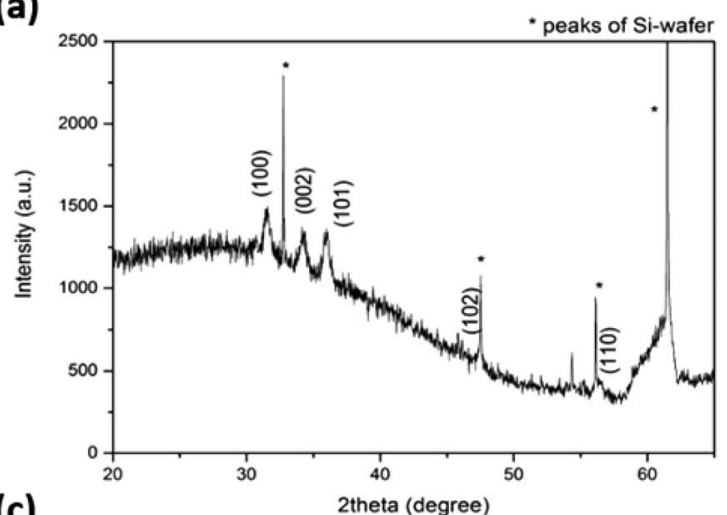

(c)

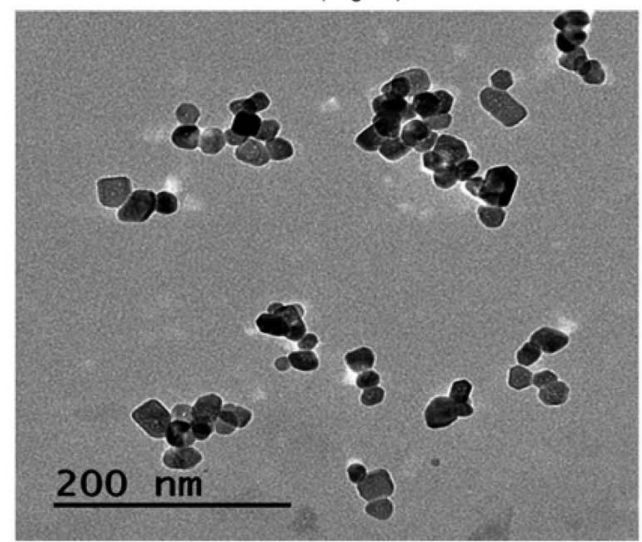

monodispersed particles sizes for both pristine and aminefunctionalized ZnO NCs in both ethanol and water media, as supported by the dynamic light scattering measurements shown in Fig. S1 in the ESI. $\uparrow$ The Fourier-transform infrared (FTIR) spectra of both the $\mathrm{ZnO}$ and $\mathrm{ZnO}-\mathrm{NH}_{2}$ NCs show some common features between the two different samples, but in the case of the $\mathrm{ZnO}-\mathrm{NH}_{2} \mathrm{NCs}$, the presence of typical vibration modes associated with the functional groups present in the 3aminopropyltrimethoxysilane molecule (APTMS) confirms the successful functionalization of the ZnO surface (Fig. S2 in the $\mathrm{ESI} \dagger)$.

\section{Biocompatibility studies}

The biocompatible or cytotoxic behaviours of both pristine and functionalized $\mathrm{ZnO}$ NCs at different concentrations were monitored in living pre-osteoblast cells from mouse calvaria. Both lactate dehydrogenase $(\mathrm{LDH})$ production and the mitochondrial activity (MTT) were recorded after 3 days of cell incubation with the nanocrystals with and without functionalization and at different concentrations, to give a complete picture of the cytotoxicity and the cell proliferation behaviour. LDH is an enzyme released by cells in case of cell membrane rupture, thus indicating a cytotoxic effect. Interestingly, the LDH tests reported in Fig. 2a and $\mathrm{c}$ for both pristine and functionalized $\mathrm{ZnO}$ NCs, respectively, evidenced no cytotoxic effect in both cases up to a concentration of $50 \mu \mathrm{g} \mathrm{mL}{ }^{-1}$ of NCs. Actually, no significant differences were registered in

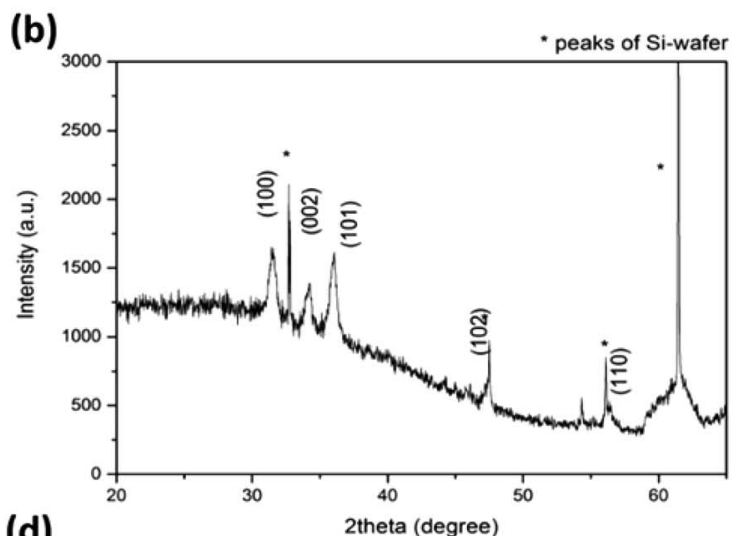

(d)

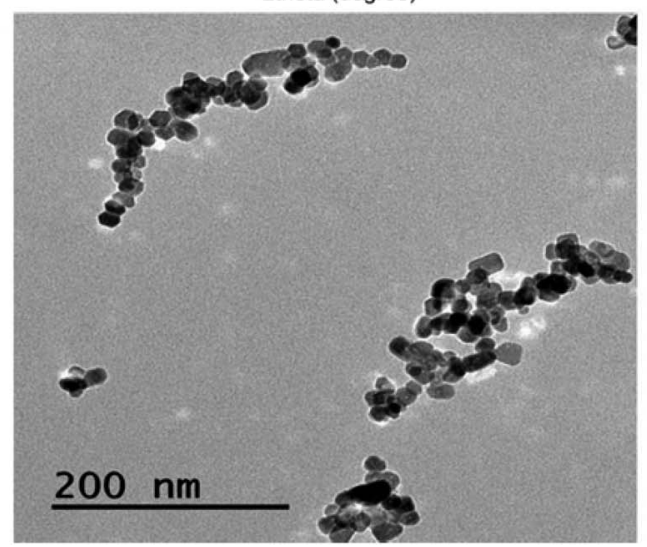

Fig. 1 Structural and morphological characterization: XRD patterns for (a) $\mathrm{ZnO}$ and (b) $\mathrm{ZnO}-\mathrm{NH}_{2} \mathrm{NCs}$; TEM micrographs of (c) $\mathrm{ZnO}$ and (d) $\mathrm{ZnO}-$ $\mathrm{NH}_{2} \mathrm{NCs}$. 
(a)

.

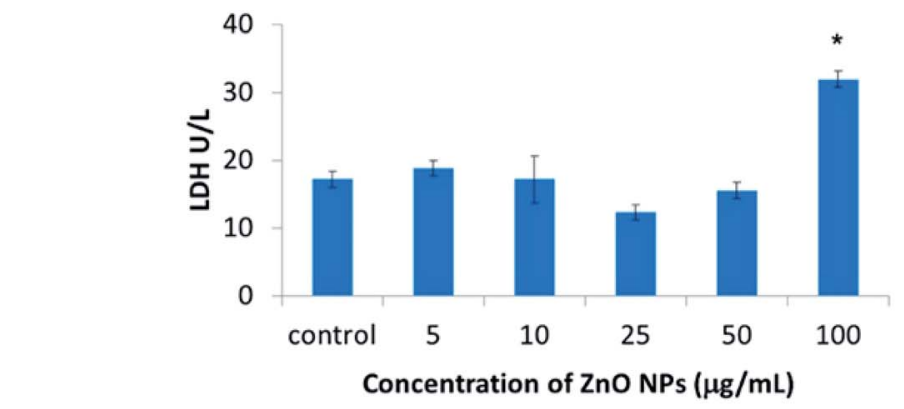

(c)

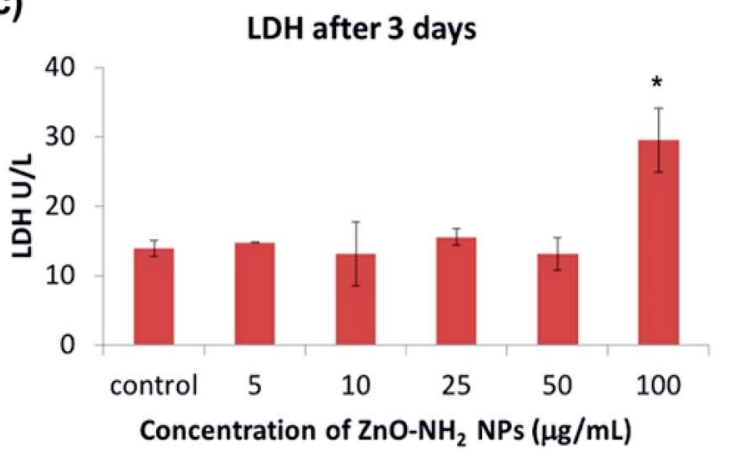

(b)

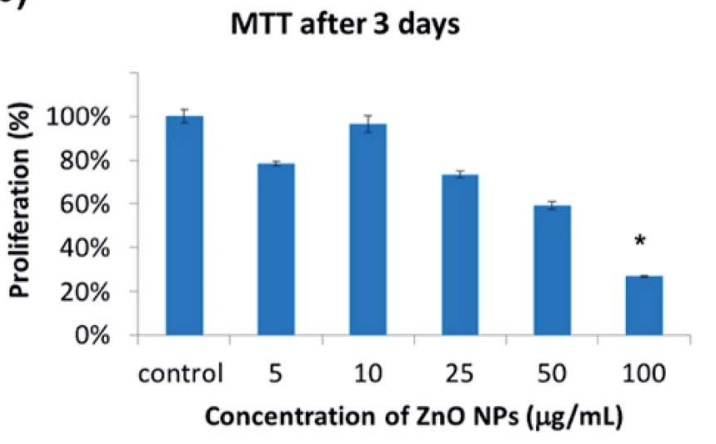

(d)

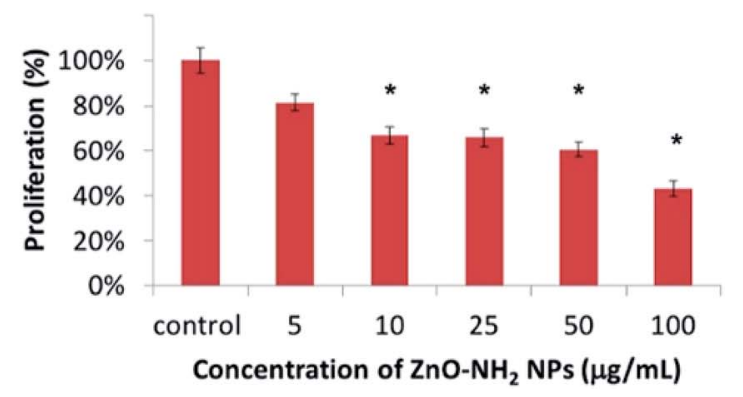

Fig. 2 In vitro biocompatibility assays: cytotoxicity by LDH released into the medium after 3 days of incubation with different concentrations of the (a) $\mathrm{ZnO}$ and (c) $\mathrm{ZnO}-\mathrm{NH}_{2}$ NCs. Proliferation results in terms of mitochondrial activity (MTT) after 3 days of incubation and with different concentrations of (b) $\mathrm{ZnO}$ and (d) $\mathrm{ZnO}-\mathrm{NH}_{2} \mathrm{NCs}(p<0.05$, significant differences compared to the control are denoted by an asterisk (*)).

comparison with the control test. In contrast, a concentration of $100 \mu \mathrm{g} \mathrm{mL}{ }^{-1}$ for both pristine $\mathrm{ZnO}$ NCs and $\mathrm{ZnO}-\mathrm{NH}_{2}$ NCs exhibited a cytotoxic effect on pre-osteoblast cells, displaying a double quantity of LDH produced with respect to the control.

The MTT proliferation test is based on the ability of mitochondrial enzymes to reduce the MTT molecule to formazan. This measurement is commonly related to the cell viability and proliferation, as previously reported in the literature..$^{32}$ According to Fig. $2 \mathrm{~b}$ and $\mathrm{d}$, both pristine and functionalized ZnO NCs show adequate cell proliferation up to a certain concentration: in general, a decrease in mitochondrial activity occurred upon an increase in the concentration of NCs with respect to the control without nanocrystals. The proliferation ranges from 90 to $70 \%$ up to a concentration of $25 \mu \mathrm{g} \mathrm{mL}^{-1}$ (compared to the control), then a slight decrease occurs for $50 \mu \mathrm{g} \mathrm{mL} \mathrm{mL}^{-1}(\approx 60 \%)$ both for the pristine and functionalized NCs. Regarding the highest concentration of $100 \mu \mathrm{g} \mathrm{mL} \mathrm{m}^{-1}$, there is a significant reduction of the proliferation down to $27 \%$ for ZnO NCs and $43 \%$ for $\mathrm{ZnO}-\mathrm{NH}_{2}$ NCs compared to the control. These results are in line with the LDH test. Therefore, both the LDH and MTT assays highlighted the great biocompatibility of $\mathrm{ZnO}$ and $\mathrm{ZnO}-$ $\mathrm{NH}_{2}$ up to a concentration of $50 \mu \mathrm{g} \mathrm{mL} \mathrm{m}^{-1}$. On the other hand, a concentration of $100 \mu \mathrm{g} \mathrm{mL} \mathrm{m}^{-1}$ showed cytotoxic activity and inhibited cell proliferation. This cytotoxic effect is generally reported in the literature ${ }^{10,26}$ as an intracellular release of cytotoxic $\mathrm{Zn}^{2+}$ cations due to $\mathrm{ZnO}$ dissolution, or as a consequence of oxidative stress by ROS, due to the presence of intracellular $\mathrm{ZnO}^{33}$
In order to gain further information on the biocompatibility behaviour, another assay was performed. The cells were cultured up to $70 \%$ confluence and then treated with the nanocrystals (at different concentrations and with or without functionalization). This procedure was necessary to simulate the interaction between pre-formed bone tissue and antibacterial agents, in order to analyse how they may affect the viability of the tissue. In this case, the proliferation via MTT was measured after $24 \mathrm{~h}$ of incubation (Fig. 3) and the cell morphology was studied under a fluorescence microscope after 4 days of incubation (Fig. 4). The values of the MTT tests are of the same order of the control up to a concentration of $50 \mu \mathrm{g}$ $\mathrm{mL}^{-1}$ for pristine ZnO NCs. Actually, the mitochondrial activity is around $100 \%$ or higher compared to the control, with a peak in the mitochondrial activity for a concentration of $25 \mu \mathrm{g} \mathrm{mL} \mathrm{m}^{-1}$, where the proliferation increased up to $130 \%$. Unfortunately, a significant decrease occurred in relation to the highest concentration $\left(100 \mu \mathrm{g} \mathrm{mL}{ }^{-1}\right)$, where the mitochondrial activity dropped down to $41 \%$. These results are indeed comparable to what is reported in Fig. 2, again showing the concentrationdependent biocompatibility of the ZnO NCs.

The results of $\mathrm{ZnO}-\mathrm{NH}_{2}$ are similar, with just a few differences. The best proliferation value was obtained for a concentration of $25 \mu \mathrm{g} \mathrm{mL} \mathrm{m}^{-1}$, but the peak is less pronounced. Interestingly, a concentration of $100 \mu \mathrm{g} \mathrm{mL} \mathrm{m}^{-1}$ did not show significant differences and the mitochondrial activity was still close to that of the control. This result highlights the first difference between pristine and functionalized ZnO NCs. 
(a)

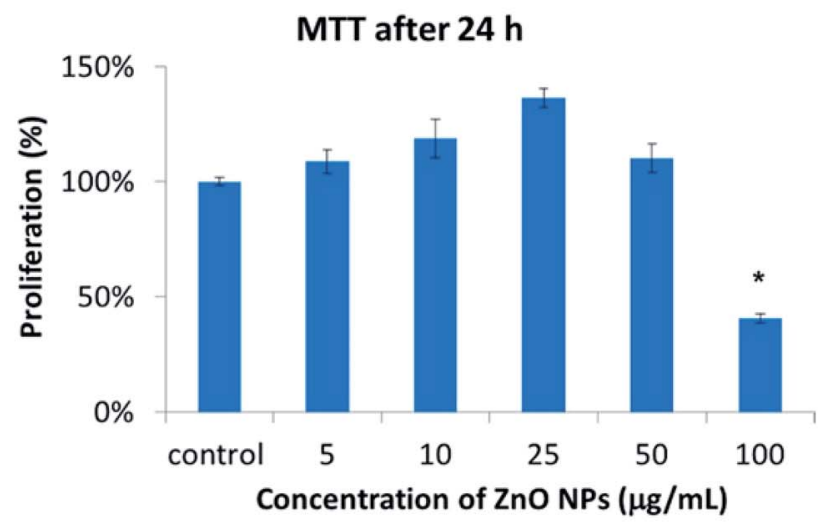

(b)

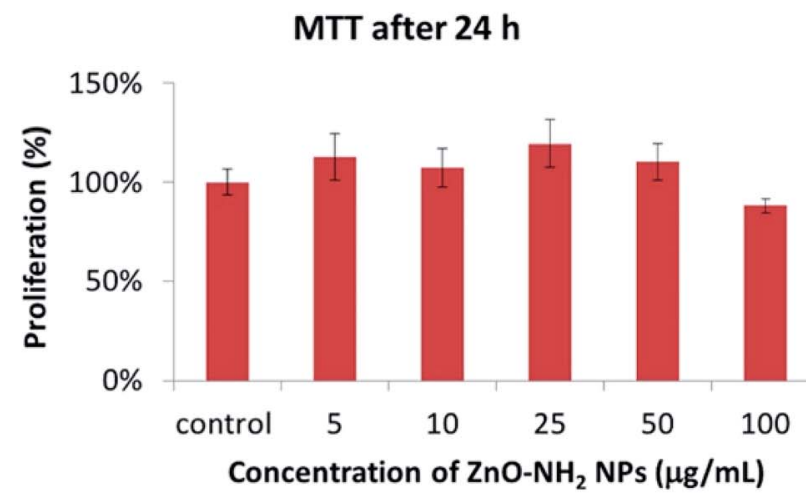

Fig. 3 Proliferation results in terms of MTT of MC3T3-E1 (at 70\% confluence) and incubated for 1 day with different concentrations of (a) $\mathrm{ZnO}$ and (b) $\mathrm{ZnO}-\mathrm{NH}_{2} \mathrm{NCs}(p<0.05$, significant differences compared to the control denoted by an asterisk $(*))$.

Confocal microscope images gave further information and allowed the investigation of the cell morphology after ZnO NC incubation. Actin was stained with Atto565-conjugated phalloidin (red) and nuclei were stained with DAPI (blue). Fig. 4 shows the typical well-spread morphology of the osteoblasts after incubation with $\mathrm{ZnO} \mathrm{NCs}$ at $25 \mu \mathrm{g} \mathrm{mL}^{-1}$. In addition, further images at the other concentrations are reported in Fig. S3 and S4 in the ESI. $\dagger$ Note that there is a slight increase in the number of cells after incubation with the nanoparticles at $25 \mu \mathrm{g} \mathrm{mL} \mathrm{m}^{-1}$, which was confirmed by an increase in the cellular thickness from $73 \pm 10 \mu \mathrm{m}$ for the control to $123 \pm 15 \mu \mathrm{m}$ in the presence of the ZnO NCs. On the contrary, at a higher concentration of pristine ZnO NCs $\left(100 \mu \mathrm{g} \mathrm{mL}^{-1}\right)$, the cells exhibited a spherical morphology, non-defined actin filaments and reduced confluence, indicating a clear cytotoxic effect at this concentration. These results confirm the previous results, evidencing the good biocompatibility of the $\mathrm{ZnO}$ NCs up to $50 \mu \mathrm{g} \mathrm{mL} \mathrm{m}^{-1}$. $^{7}$

Regarding the functionalized $\mathrm{ZnO}-\mathrm{NH}_{2} \mathrm{NCs}$, this cytotoxic effect was less noticeable, because the cells in contact with $100 \mu \mathrm{g}$ $\mathrm{mL}^{-1}$ show a well-spread morphology and still have fluorescent actin filaments, but the grade of confluence was inferior compared to that of the control cells. $\mathrm{ZnO}-\mathrm{NH}_{2}$ was again confirmed to be

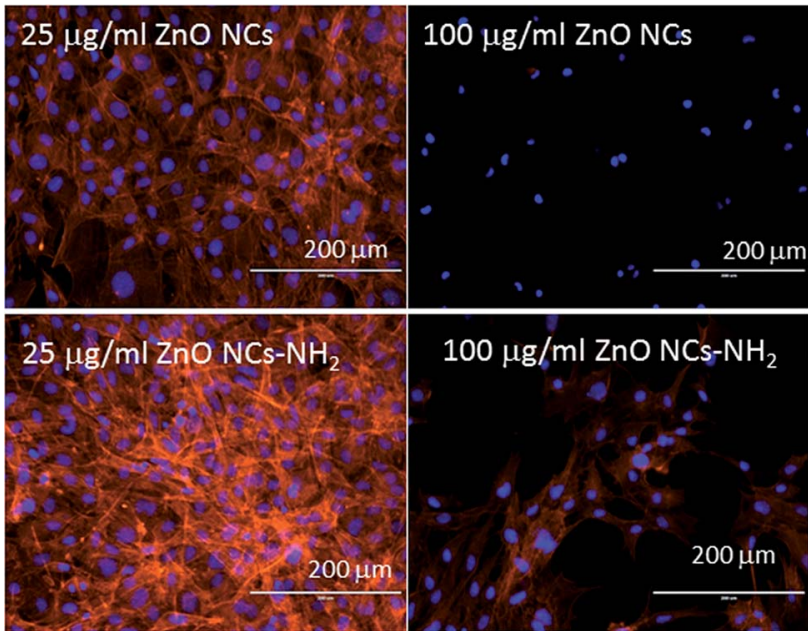

Fig. 4 Confocal microscopy images of pre-osteoblasts cultured up to $70 \%$ confluence after incubation for 4 days with $\mathrm{ZnO}$ and $\mathrm{ZnO}-\mathrm{NH}_{2}$ $\mathrm{NCs}$ at different concentrations. All confocal images were obtained under the same conditions and show the $Z$ projection of different images taken at different depths.

more biocompatible, especially for the highest sample concentration of $100 \mu \mathrm{g} \mathrm{mL} \mathrm{m}^{-1}$, under these experimental conditions.

\section{Differentiation assay: ALP}

Differentiation is a process by which unspecialized cells, preosteoblasts, become specialized cells with the function to restore bone. For this purpose, the activity of ALP (alkaline phosphatase), a marker enzyme for determining osteoblast phenotype was monitored. In particular, the ALP activity of both kinds of ZnO NCs was determined after 10 days of incubation in pre-osteoblast cells. In Fig. 5a, it is possible to observe the progressive decrease in the ALP activity upon an increase in the concentration of the $\mathrm{ZnO} \mathrm{NCs}$, and even in this case the lowest value was for $100 \mu \mathrm{g} \mathrm{mL}{ }^{-1}$. Regarding the total protein content (top of Fig. S5 in the ESI $\dagger$ ), the trend is very similar to that of the ALP activity. No significant differences are observed up to a concentration of $10 \mu \mathrm{g} \mathrm{mL}{ }^{-1}$, while there is a drop from $25 \mu \mathrm{g}$ $\mathrm{mL}^{-1}$ to higher concentration values. On the other hand, the $\mathrm{ZnO}-\mathrm{NH}_{2}$ NCs showed different behaviour. As can be observed in Fig. 5b, there are no significant differences compared to the control in terms of the ALP activity, evidencing that there is no apparent inhibition at the lower concentrations of nanoparticles (below $100 \mu \mathrm{g} \mathrm{mL}{ }^{-1}$ ). At the highest concentration of $100 \mu \mathrm{g} \mathrm{mL}{ }^{-1}$, around $20 \%$ decrease in the ALP activity was obtained. A similar trend was observed for the total protein content, as shown in the part of Fig. S5 in the ESI. $\dagger$

The cell morphology under a bright field optical microscope was also recorded at every concentration, both for the pristine and functionalized incubated NCs (see Fig. S6 and S7 in the ESI $\dagger$ ). MC3T3-E1 cells exhibit a well spread morphology, with a high degree of confluence, up to a concentration of $50 \mu \mathrm{g}$ $\mathrm{mL}^{-1}$ for pristine $\mathrm{ZnO}$ NCs. As observed above, the cells treated with $100 \mu \mathrm{g} \mathrm{mL}{ }^{-1}$ of $\mathrm{ZnO}$ NCs present a spherical morphology, indicating cell sufferance and death, with a minor grade of confluence. 
(a) ALP after 10 days

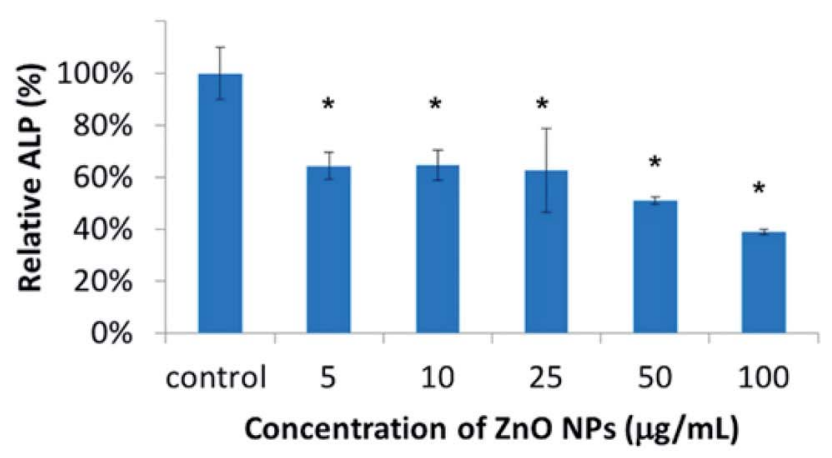

(b) ALP after 10 days

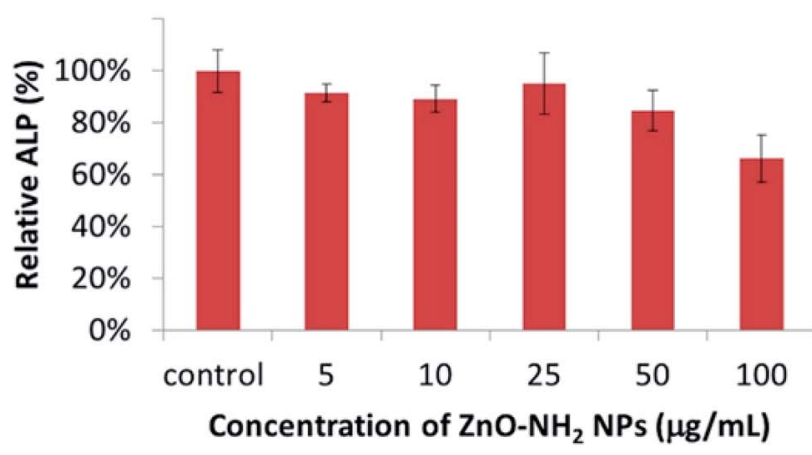

Fig. 5 Differentiation assays in terms of ALP after 10 days of incubation with the (a) $\mathrm{ZnO}$ and (b) $\mathrm{ZnO}-\mathrm{NH}_{2} \mathrm{NCs}$ at different concentrations ( $p<0.05$, significant differences compared to the control denoted by an asterisk $(*))$.

Regarding the cells treated with $\mathrm{ZnO}-\mathrm{NH}_{2}$ NCs for ten days at different concentrations, in all cases a well-spread morphology of MC3T3-E1 cells was observed, including the highest concentration of $100 \mu \mathrm{g} \mathrm{mL}{ }^{-1}$ for $\mathrm{ZnO}-\mathrm{NH}_{2}$ NPs. We observed a slightly lower confluence for the most concentrated sample with respect to the others. However, these optical microscope images confirmed the results of the ALP activity and total protein content, showing the prominent biocompatible and osteoinductive role, even at high concentrations, of the $\mathrm{ZnO}-\mathrm{NH}_{2} \mathrm{NCs}$.

\section{Antimicrobial activity}

The antimicrobial activity of different NCs was determined against Gram positive ( $S$. aureus) and Gram negative (E. coli) bacteria at the planktonic stage, after $24 \mathrm{~h}$ of incubation at different concentrations. Fig. 6 summarizes these results in terms of the logarithmic scale of CFU (colony-forming unit) quantification. The obtained results show a remarkable antimicrobial effect of both pristine $\mathrm{ZnO}$ and functionalized $\mathrm{ZnO}-$ $\mathrm{NH}_{2} \mathrm{NCs}$ against the two types of bacteria. However, there were notable differences between both strains. Regarding the antimicrobial activity against $E$. coli, it is very interesting to notice that in particular, there is no effect of NC concentration, each one showing a $100 \%$ reduction in bacteria viability. The same behaviour was observed for both pristine and functionalized nanocrystals. On the other hand, the activity against $S$. aureus was slightly different.

A peak in the antimicrobial activity was obtained for a concentration of $25 \mu \mathrm{g} \mathrm{mL}{ }^{-1}$ for both the $\mathrm{ZnO}$ and $\mathrm{ZnO}-\mathrm{NH}_{2}$ NCs, showing a reduction in the viability of around 99.98 and 99.99\% (less than $100 \mathrm{CFU} \mathrm{mL}^{-1}$ ), respectively. In contrast, the antimicrobial activity was reduced at a higher concentration, in particular for a concentration of $50 \mu \mathrm{g} \mathrm{mL}{ }^{-1}$ of the $\mathrm{ZnO}-\mathrm{NH}_{2}$ NCs, resulting in only $99.85 \%$ of bacteria inactivation (in this case the concentration was higher at $10^{2} \mathrm{CFU} \mathrm{mL} \mathrm{mL}^{-1}$, which could be considered not effective). This performance could be explained by the aggregation of the nanocrystals when dispersed in PBS, as previously observed by some of our group. ${ }^{31}$ In fact, by increasing the concentration, there is greater probability of forming huge aggregates, which means a lower surface area to volume ratio, and thus reduced contact with the $S$. aureus population. This behaviour was not detected with $E$. coli probably because of the different shape and resistance. In fact, $E$. coli exhibits an elongated shape, while $S$. aureus a round shape, thus aggregated NCs have a major probability of coming into contact with $E$. coli. In addition, $S$. aureus is a more resistant and pathogenic bacteria compared to E. coli. For further information, Table S1† summarizes the reduction in the bacteria viability.

\section{Experimental}

\section{ZnO synthesis and functionalization}

ZnO NCs were synthesized through a novel microwave-assisted synthesis approach using zinc acetate dihydrate $(0.1 \mathrm{M})$ and potassium hydroxide $(0.2 \mathrm{M})$ precursors (both from SigmaAldrich) dispersed in methanol as a solvent. The solution containing the zinc precursor was prepared and stirred directly in the reactor vessel. In order to initiate zinc oxide nucleation, 0.48 $\mu \mathrm{L}$ of double-distilled water were added and then it was mixed together with the $\mathrm{KOH}$ solution in the reactor vessel. The resulting solution was put into a microwave oven for 30 minutes under controlled pressure at a temperature of $60{ }^{\circ} \mathrm{C}$. After this time, the colloidal dispersion was collected and centrifuged for 10 minutes at $5000 \mathrm{rpm}$ (3500 rcf), in order to separate the methanol and reaction residuals from the newly-formed $\mathrm{ZnO}$ NCs. The surfactant was then removed and the precipitate was dispersed and washed in $15 \mathrm{~mL}$ of ethanol twice. The asobtained ZnO NCs pellet was suspended in fresh ethanol to give the final colloidal suspension.

The functionalization step of ZnO NCs with amino groups $\left(\mathrm{NH}_{2}\right)$ was carried out by combining the nanocrystals with 3aminopropyltrimethoxysilane, (APTMS, 97\%, Sigma), as already reported in ref. 10 . In more detail, $100 \mathrm{mg}(1.23 \mathrm{mmol})$ of $\mathrm{ZnO}$ $\mathrm{NCs}$, dispersed in ethanol, were heated to $80{ }^{\circ} \mathrm{C}$ in a $100 \mathrm{~mL}$ round-bottomed flask under continuous stirring and nitrogen gas flow. 15 minutes later, $21.4 \mu \mathrm{L}$ of APTMS $(0.123 \mathrm{mmol}$, $22.05 \mathrm{mg}$, corresponding to $10 \mathrm{~mol} \%$ of the total $\mathrm{ZnO}$ amount) was added to the solution. The obtained mixture was refluxed under a nitrogen gas flow for $6 \mathrm{~h}$ and successively washed twice by separating the NCs under centrifugation (10 min, 10000 rpm) to remove the unbound APTMS molecules. 

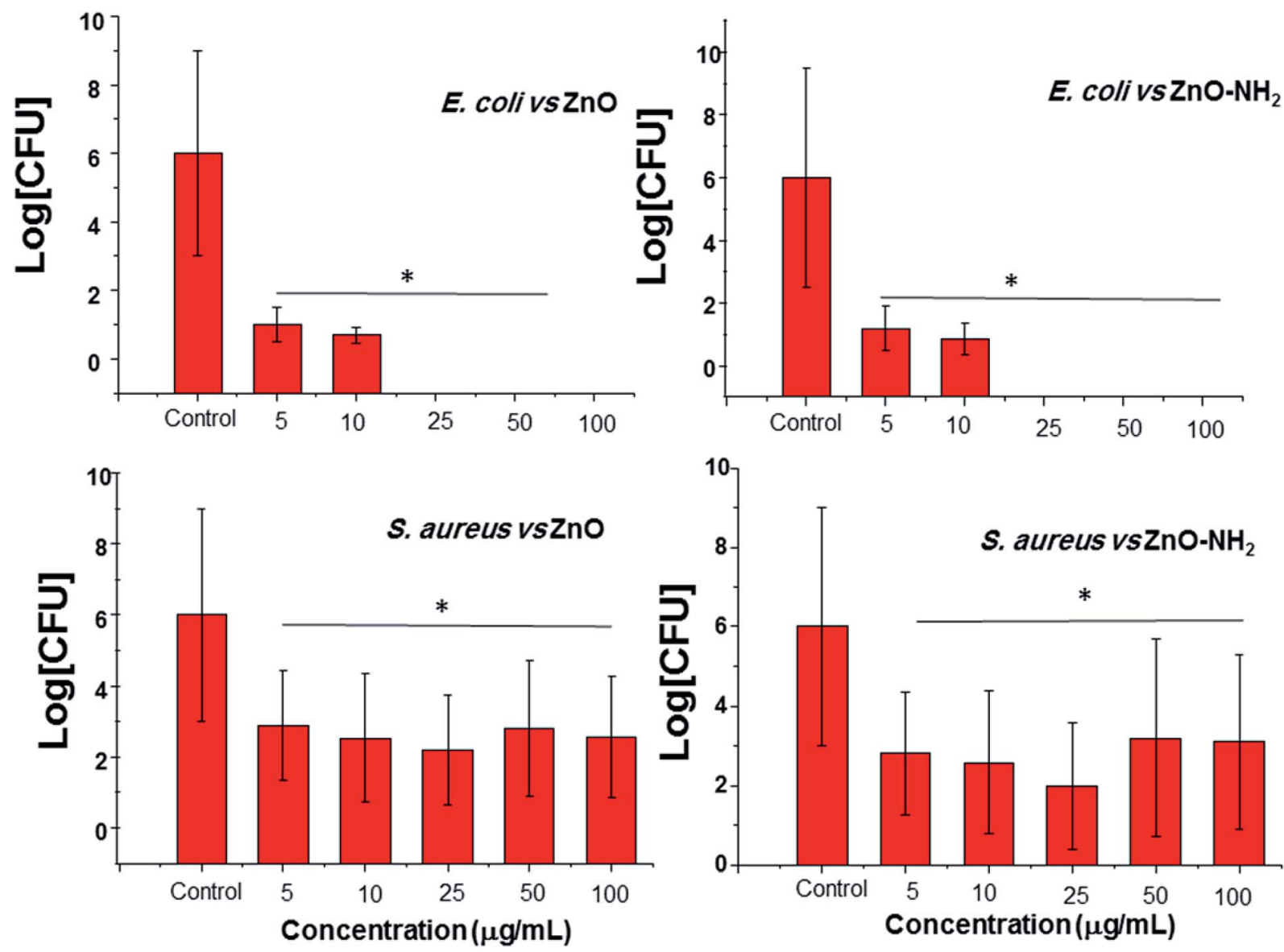

Fig. 6 Logarithmic scale of CFU per $\mathrm{mL}$ of $E$. coli and S. aureus at the planktonic stage incubated for $24 \mathrm{~h}$ in the presence of different concentrations of $\mathrm{ZnO}$ and $\mathrm{ZnO}-\mathrm{NH}_{2} \mathrm{NCs}(p<0.05$, significant differences compared to the control denoted by an asterisk (*) in absolute value).

\section{Characterization}

The ZnO NCs obtained from the microwave-assisted synthesis were characterized by comparing data from different batches in order to confirm the repeatability of the synthesis. In particular, the samples were analyzed by XRD in order to investigate the crystalline structure. A Panalytical X'Pert diffractometer in configuration 0-2 $\theta$ Bragg-Brentano was employed, equipped with a $\mathrm{Cu}-\mathrm{K} \alpha$ radiation source $(\lambda=1.54 \AA$, $40 \mathrm{kV}$ to $30 \mathrm{~mA})$. The samples were prepared by depositing the colloidal solution drop by drop on a silicon wafer, in order to have a sufficiently thick layer of nanocrystals. The XRD analysis was carried out with a step size of $0.02^{\circ}(2 \theta)$, in the $2 \theta$ range of $20-70^{\circ}$ with an acquisition time of $100 \mathrm{~s}$.

Transmission electron microscopy (TEM) characterization was also used to assess the morphology, size, shape and crystallinity of the nanocrystals. The samples were diluted in ultrapure ethanol (99\%) up to a concentration of $200 \mu \mathrm{g} \mathrm{mL} \mathrm{m}^{-1}$ and then one drop was deposited on a copper grid with carbon mesh for high-resolution (HR-TEM) analysis. The measurements were performed with JEM 2100HT (JEOL) multipurpose analytical HR-TEM, with an accelerating voltage of $200 \mathrm{kV}$ and point resolution of $0.25 \mathrm{~nm}$. HR-TEM images were acquired using a charge coupled device (CCD) camera.

\section{Cell culture conditions}

MC3T3-E1, pre-osteoblasts cells from mouse calvaria were used. Cells were grown in complete Dulbecco's modified Eagle's medium ( $\alpha$-DMEM, Sigma Chemical Company, St. Louis, MO, USA) supplemented with $2 \mathrm{mM}$ L-glutamine (BioWhittaker), 100 $\mu \mathrm{g} \mathrm{mL} \mathrm{mL}^{-1}$ penicillin (BioWhittaker), $100 \mathrm{~g} \mathrm{~mL}^{-1}$ streptomycin (BioWhittaker) and 10\% fetal bovine serum (FBS, Gibco) at $37{ }^{\circ} \mathrm{C}$ under atmosphere conditions of $95 \%$ humidity and $5 \%$ $\mathrm{CO}_{2}$. The medium was changed every day until confluence was reached $\approx 90 \%$ in a P75 flask. Then, the cultures were trypsinized with a solution of $0.05 \%(\mathrm{w} / \mathrm{v})$ trypsin and $0.02 \%(\mathrm{w} / \mathrm{v})$ EDTA in sterile phosphate buffered saline (Sigma-Aldrich) and counted with a Neubauer hemocytometer. Cells were then centrifuged at $310 \mathrm{~g}$ for $10 \mathrm{~min}$ and suspended in fresh medium at a density of $2 \times 10^{4}$ cells per mL.

In cellular assays, the behavior of both the pristine $\mathrm{ZnO}$ and $\mathrm{ZnO}-\mathrm{NH}_{2}$ NCs was studied at the following concentrations: 5, $10,25,50$, and $100 \mu \mathrm{g} \mathrm{mL} \mathrm{m}^{-1}$. The desired amount of NCs was taken away from the stock solutions in ethanol, centrifuged to pellet the NCs, discarding the ethanol, and then the NCs were dispersed in the final volume of cell culture medium. ZnO-free suspensions were used as a control. In addition, two different experiments were performed. In the first, cells and the $\mathrm{ZnO}$ 
nanostructures were put into contact at the same time, to analyze the situation when stem cells and antimicrobial agents simultaneously meet. In the second assay, cells were cultured up to $70 \%$ confluence, and then the nanocrystals were added. This procedure simulates the interaction between pre-formed bone tissue and an antibacterial agent, in order to analyse how they may affect the viability of the tissue.

\section{Cytotoxicity test - LDH}

LDH activity was determined in culture medium in contact with nanocrystals after 3 days of incubation. The activity of $\mathrm{LDH}$ released by the MC3T3-E1 cells is directly related to the rupture of the plasmatic membrane (cell death) that, when broken, releases all organelles and enzymes present in the cytoplasm. For this purpose, $0.750 \mathrm{~mL}$ of cell suspension with a concentration of $1.33 \times 10^{4}$ cells per $\mathrm{mL}$ and $0.250 \mathrm{~mL}$ of NC suspensions with the desired concentration were added in each plate. After adding NCs in the cell suspensions, the well plates were left to incubate under $\mathrm{CO}_{2}(5 \%)$ atmosphere at $37^{\circ} \mathrm{C}$ for 3 days. Measurements were performed using a commercial kit (Spinreact) at an absorbance at $340 \mathrm{~nm}$ with a UV-visible spectrophotometer. Two replicates were done for each concentration.

\section{Mitochondrial activity - MTT}

To evaluate the cell mitochondrial activity of living cells on the different plates as well as their surroundings after 1 and 3 days of incubation, the MTT method was employed. This method is based on the reduction of 3-(4,5-dimethylazol-2-yl)-2,5diphenyltetrazolium (yellow) to blue formazan. This measurement was used in terms of cell proliferation. For this purpose, $0.750 \mathrm{~mL}$ of MC3T3-E1 cells in a concentration of $10^{4}$ cells per $\mathrm{mL}$ in complete medium were cultured in 24-well plates in the presence of $0.250 \mathrm{~mL}$ of $\mathrm{ZnO}$ or $\mathrm{ZnO}-\mathrm{NH}_{2} \mathrm{NC}$ suspension at different concentrations and incubated in a $5 \% \mathrm{CO}_{2}$ atmosphere at $37{ }^{\circ} \mathrm{C}$ for 3 days. This test was replicated for preformed bone tissue, where NCs were incubated for 1 day with cells at $70 \%$ confluence. After this time, the culture medium was substituted with $1 \mathrm{~mL}$ of $\alpha$-MEM and $125 \mu \mathrm{L}$ of MTT solution $\left(5 \mathrm{mg} \mathrm{mL}^{-1}\right.$ in PBS $1 \times$ ) was added. Samples were incubated for $4 \mathrm{~h}$ at $37{ }^{\circ} \mathrm{C}$ and $5 \% \mathrm{CO}_{2}$ in the dark. Then, the medium was removed and $500 \mu \mathrm{L}$ of a $0.4 \mathrm{M} \mathrm{HCl}$-isopropanol solution was added. At the end, the absorbance at $570 \mathrm{~nm}$ was measured. Two replicates were done for each concentration.

\section{Cell morphology studies}

The morphology of pre-osteoblast cells MC3T3-E1 was studied using an AMG EVOS fl LED fluorescence microscope. For this purpose, cells were cultured up to $70 \%$ confluence, and then the medium was removed. Afterwards, $0.750 \mathrm{~mL}$ of complete $\alpha$ MEM and $0.250 \mathrm{~mL}$ of NC suspensions with the desired concentrations were added to each plate. Samples were incubated for 4 days. After this time, adherent cells were fixed with paraformaldehyde (4\% in PBS) for 30 minutes. Then, Atto 565conjugated phalloidin and DAPI were added to each plate to stain the cell actin in red and cell nuclei in blue, respectively.

\section{Differentiation assay: alkaline phosphatase activity - ALP}

To evaluate the differentiation of MC3T3-E1, ALP measurements were employed. ALP is an enzyme present in most organisms, found in high quantities in the bone, liver, placenta, intestine and kidney. ALP activity of the cells growing in contact with $\mathrm{ZnO}$ nanostructures was utilized as a marker of cellular differentiation in the evaluation of the phenotype expression of osteoblasts.

For this purpose, MTC3T3-E1 pre-osteoblastic cells $\left(10^{4}\right.$ cells per $\mathrm{mL}$ ) were cultured directly in a 24-well plate and incubated for 10 days in contact with $\mathrm{ZnO}$ and $\mathrm{ZnO}-\mathrm{NH}_{2}$ under standard culture conditions $\left(37{ }^{\circ} \mathrm{C}, 5 \% \mathrm{CO}_{2}\right)$ using $\alpha$-MEM completed medium supplemented with beta-glycerolphosphate $(50 \mathrm{mg}$ $\left.\mathrm{mL}^{-1}\right)$ and $\mathrm{L}$-ascorbic acid (10 $\left.\mathrm{mM}\right)$. In particular, $0.750 \mathrm{~mL}$ of cell suspensions with a concentration of $1.33 \times 10^{4}$ cells per $\mathrm{mL}$ and $0.250 \mathrm{~mL}$ of NCs suspensions with the desired concentration were added to each plate. Two replicates were done for each samples in two independent assays $(n=4)$.

After incubation for 10 days, the medium was taken off and every well plate was washed twice with PBS ( $\mathrm{pH}$ 7.4). Successively, samples were frozen and before the measurement they were frozen and unfrozen 3 times in order to break the cell membrane and release ALP. ALP was measured using a Spinreact kit.

\section{CFU counting method}

To examine the bactericidal effect of ZnO NCs on bacteria, at the planktonic stage, direct incubation with bacteria solution in PBS was carried out. Both E. coli 25922 and S. aureus ATCC29213 (methicillin-sensitive) were used. In this case, concentrations of $5,10,25,50$, and $100 \mu \mathrm{g} \mathrm{mL}{ }^{-1}$ were used in order to determine their effectivity. For this purposes $0.750 \mathrm{~mL}$ of bacteria suspensions in PBS with a concentration of $1.33 \times 10^{6}$ bacteria per $\mathrm{mL}$ and $0.250 \mathrm{~mL}$ of NC suspensions with the desired concentration were added to each well of a 24 -well plate. Then, NC and bacteria suspensions were incubated for $24 \mathrm{~h}$ under orbital stirring at $37{ }^{\circ} \mathrm{C}$. Two different experiments were performed in triplicate. The quantification of living bacteria was determined by CFUs in agar. In order to be more accurate, the original solution and different dilutions (1/10, 1/100 and 1/1000 dilutions) were used. ${ }^{34}$ Thus, $20 \mu \mathrm{L}$ of such solutions was seeded onto trypsin soy agar (TSA), incubated at $37{ }^{\circ} \mathrm{C}$ overnight and subsequently the number of CFUs was counted. Positive controls containing bacteria were also used and the experiments were performed in triplicate.

\section{Statistical analysis}

Data are expressed as average/mean \pm standard deviation in the two experiments. The software Statistical Package for the Social Sciences (SPSS) version 11.5 was used to perform statistical analysis. The variance analysis (ANOVA) was utilized for statistical comparisons. Scheffé's test was used for the post hoc evaluation of the differences among the groups. In all statistical evaluations, $p<0.05$ was considered as statistically significant. 


\section{Conclusions}

In this work, uniform and highly crystalline $\mathrm{ZnO}$ nanoparticles were synthesized using an innovative microwave-assisted solvothermal synthesis to obtain nanocrystals of $20 \mathrm{~nm}$ in diameter. The results highlighted that $\mathrm{ZnO}$ NCs show great biocompatibility towards pre-osteoblast cells and promising antimicrobial activity against $E$. coli and $S$. aureus. Moreover, the biocompatibility and antibacterial assays performed on the functionalized $\mathrm{ZnO}-\mathrm{NH}_{2}$ NCs also demonstrated that fine control over the $\mathrm{ZnO}$ chemical surface by aminefunctionalization further improved both the biocompatibility in terms of cell differentiation and proliferation and their antimicrobial capability. These findings open up new horizons in the use of ZnO NCs as a highly biocompatible nanoantibiotic for bone tissue engineering.

\section{Author contributions}

The manuscript was written through contributions of all of the authors. All authors have given approval of the final version of the manuscript.

\section{Conflicts of interest}

The authors declare no conflict of interest.

\section{Acknowledgements}

Part of this work received funding from the European Research Council (ERC) under the European Union's Horizon 2020 research and innovation programme (grant agreement No 678151 - Project Acronym “TROJANANOHORSE” - ERC Starting Grant and grant agreement No 694160 - Project Acronym "VERDI"- ERC Advanced Grant). Moreover, this work was also supported by grant MAT2015-64831-R from MINECO, Spain.

\section{References}

1 D. Campoccia, L. Montanaro and C. R. Arciola, Biomaterials, 2006, 27, 2331-2339.

2 V. Cauda, B. Onida, B. Platschek, L. Muhlstein and T. Bein, J. Mater. Chem., 2008, 18, 5888-5899.

3 B. González, M. Colilla, J. Díez, D. Pedraza, M. Guembe, I. Izquierdo-Barba and M. Vallet-Regí, Acta Biomater., 2018, 68, 261-271.

4 A. J. Huh and Y. J. Kwon, J. Controlled Release, 2011, 156, 128145.

5 l. Wang, C. Hu and L. Shao, Int. J. Nanomed., 2017, 12, 12271249.

6 https:/www.accessdata.fda.gov/scripts/cdrh/cfdocs/cfcfr/ CFRSearch.cfm?fr=182.8991, accessed 2nd July 2018.

7 M. Carmona, Y. Guńko and M. Vallet-Regí, Nanomaterials, 2018, 8, 268.

8 Z. Ping, W. Zhengyang, L. Xia, L. Xiangmei, W. Shuilin, K. W. K. Yeung, W. Xianbao, C. Zhenduo, Y. Xianjin and P. K. Chu, Adv. Mater. Interfaces, 2016, 3, 1500494.
9 L. Racca, M. Canta, B. Dumontel, A. Ancona, T. Limongi, N. Garino, M. Laurenti, G. Canavese and V. Cauda, in Smart Nanoparticles for Biomedicine, ed. G. Ciofani, Elsevier, 2018, pp. 171-187, DOI: 10.1016/B978-0-12814156-4.00012-4.

10 B. Dumontel, M. Canta, H. Engelke, A. Chiodoni, L. Racca, A. Ancona, T. Limongi, G. Canavese and V. Cauda, J. Mater. Chem. B, 2017, 5, 8799-8813.

11 V. Cauda, R. Gazia, S. Porro, S. Stassi, G. Canavese, I. Roppolo and A. Chiolerio, in Handbook of Nanomaterials Properties, ed. B. Bhushan, D. Luo, S. R. Schricker, W. Sigmund and S. Zauscher, Springer, 2014, ch. 5, vol. 2014, pp. 137-177.

12 M. Laurenti, S. Stassi, G. Canavese and V. Cauda, Adv. Mater. Interfaces, 2017, 4, 1600758.

13 S. Nair, A. Sasidharan, V. V. Divya Rani, D. Menon, S. Nair, K. Manzoor and S. Raina, J. Mater. Sci.: Mater. Med., 2008, 20, 235.

14 J. W. Rasmussen, E. Martinez, P. Louka and D. G. Wingett, Expert Opin. Drug Delivery, 2010, 7, 1063-1077.

15 S. Amna, M. Shahrom, S. Azman, N. H. M. Kaus, A. Ling Chuo, B. Siti Khadijah Mohd, H. Habsah and M. Dasmawati, Nano-Micro Lett., 2015, 7, 219-242.

16 M. Laurenti and V. Cauda, Materials, 2018, 11, 314.

17 L. Grenho, F. J. Monteiro and M. P. Ferraz, J. Biomed. Mater. Res., Part A, 2014, 102, 3726-3733.

18 L. Grenho, C. L. Salgado, M. H. Fernandes, F. J. Monteiro and M. P. Ferraz, Nanotechnology, 2015, 26, 315101.

19 J. Chen, X. Zhang, H. Cai, Z. Chen, T. Wang, L. Jia, J. Wang, Q. Wan and X. Pei, Colloids Surf., B, 2016, 147, 397-407.

20 Y. Li, L. Sun and T. J. Webster, J. Biomed. Nanotechnol., 2018, 14, 536-545.

21 A. Bhowmick, S. L. Banerjee, N. Pramanik, P. Jana, T. Mitra, A. Gnanamani, M. Das and P. P. Kundu, Int. J. Biol. Macromol., 2018, 106, 11-19.

22 K. Memarzadeh, A. S. Sharili, J. Huang, S. C. F. Rawlinson and R. P. Allaker, J. Biomed. Mater. Res., Part A, 2015, 103, 981-989.

23 G. Colon, B. C. Ward and T. J. Webster, J. Biomed. Mater. Res., Part A, 2006, 78A, 595-604.

24 T. Wang, J.-C. Zhang, Y. Chen, P.-G. Xiao and M.-S. Yang, J. Trace Elem. Med. Biol., 2007, 21, 84-91.

25 B. Sommer, M. Bickel, W. Hofstetter and A. Wetterwald, Bone, 1996, 19, 371-380.

26 N. Garino, T. Limongi, B. Dumontel, M. Canta, L. Racca, M. Laurenti, M. Castellino, A. Casu, A. Falqui and V. Cauda, Nanomaterials, 2019, 9, 212.

27 K. Ocakoglu, S. Mansour, S. Yildirimcan, A. A. Al-Ghamdi, F. El-Tantawy and F. Yakuphanoglu, Spectrochim. Acta, Part A, 2015, 148, 362-368.

28 A. Sanginario, V. Cauda, A. Bonanno, K. Bejtka, S. Sapienza and D. Demarchi, RSC Adv., 2016, 6, 891-897.

29 B. Miccoli, V. Cauda, A. Bonanno, A. Sanginario, K. Bejtka, F. Bella, M. Fontana and D. Demarchi, Sci. Rep., 2016, 6, 29763.

30 N. Garino, A. Lamberti, R. Gazia, A. Chiodoni and C. Gerbaldi, J. Alloys Compd., 2014, 615, S454-S458. 
31 A. Ancona, B. Dumontel, N. Garino, B. Demarco, D. Chatzitheodoridou, W. Fazzini, H. Engelke and V. Cauda, Nanomaterials, 2018, 8, 143.

32 N. Gómez-Cerezo, S. Sánchez-Salcedo, I. Izquierdo-Barba, D. Arcos and M. Vallet-Regí, Acta Biomater., 2016, 44, 73.

33 L. Racca, M. Canta, B. Dumontel, A. Ancona, T. Limongi, N. Garino, M. Laurenti, G. Canavese and V. Cauda, in
Smart Nanoparticles for Biomedicine, ed. G. Ciofani, Elsevier, 2018, ch. 12, pp. 171-187, DOI: 10.1016/B978-012-814156-4.00012-4.

34 N. Encinas, M. Angulo, C. Astorga, M. Colilla, I. IzquierdoBarba and M. Vallet-Regí, Acta Biomater., 2019, 15, 317. 